\title{
Relationship between the Foveal Avascular Zone and Foveal Pit Morphology
}

\author{
Adam M. Dubis, ${ }^{*, 1}$ Benjamin R. Hansen, ${ }^{2,3}$ Robert F. Cooper, ${ }^{3}$ Joseph Beringer, ${ }^{4}$ \\ Alfredo Dubra, ${ }^{3,4,5}$ and Joseph Carroll*,1,3,4,5
}

Purpose. To assess the relationship between foveal pit morphology and size of the foveal avascular zone (FAZ).

Methods. Forty-two subjects were recruited. Volumetric images of the macula were obtained using spectral domain optical coherence tomography. Images of the FAZ were obtained using either a modified fundus camera or an adaptive optics scanning light ophthalmoscope. Foveal pit metrics (depth, diameter, slope, volume, and area) were automatically extracted from retinal thickness data, whereas the FAZ was manually segmented by two observers to extract estimates of FAZ diameter and area.

Results. Consistent with previous reports, the authors observed significant variation in foveal pit morphology. The average foveal pit volume was $0.081 \mathrm{~mm}^{3}$ (range, 0.022 to 0.190 $\mathrm{mm}^{3}$ ). The size of the FAZ was also highly variable between persons, with FAZ area ranging from 0.05 to $1.05 \mathrm{~mm}^{2}$ and FAZ diameter ranging from 0.20 to $1.08 \mathrm{~mm}$. FAZ area was significantly correlated with foveal pit area, depth, and volume; deeper and broader foveal pits were associated with larger FAZs.

Conclusions. Although these results are consistent with predictions from existing models of foveal development, more work is needed to confirm the developmental link between the size of the FAZ and the degree of foveal pit excavation. In addition, more work is needed to understand the relationship between these and other anatomic features of the human foveal region,

From the Departments of ${ }^{1}$ Cell Biology, Neurobiology, and Anatomy, ${ }^{4}$ Ophthalmology, and ${ }^{5}$ Biophysics, and the ${ }^{2}$ Summer Program for Undergraduate Research, Medical College of Wisconsin, Milwaukee, Wisconsin; and the ${ }^{3}$ Department of Biomedical Engineering, Marquette University, Milwaukee, Wisconsin.

Presented in part at the 2010 OSA Fall Vision Meeting, Rochester, New York, October 22-24, 2010.

Supported by a Research to Prevent Blindness Career Development Award (JC); a Burroughs Wellcome Fund Career Award at the Scientific Interface (AD); National Institutes of Health Grants P30EY001931, T32EY014537, and R01EY017607; E. Matilda Ziegler Foundation for the Blind; Thomas M. Aaberg Sr; Retina Research Fund; R.D. and Linda Peters Foundation; and an unrestricted departmental grant from Research to Prevent Blindness. This investigation was conducted in a facility constructed with support from Research Facilities Improvement Program Grant C06 RR016511 from the National Center for Research Resources, National Institutes of Health.

Submitted for publication August 28, 2011; revised January 4, 2012; accepted January 30, 2012.

Disclosure: A.M. Dubis, None; B.R. Hansen, None; R.F. Cooper None; J. Beringer, None; A. Dubra, None; J. Carroll, None

*Each of the following is a corresponding author: Adam M. Dubis, Department of Cell Biology, Neurobiology, and Anatomy, Medical College of Wisconsin, 8701 Watertown Plank Road, Milwaukee, WI 53226; adubis@mcw.edu.

Joseph Carroll, Department of Ophthalmology, Medical College of Wisconsin, 925 N 87th Street, Milwaukee, WI 53226; jcarroll@mcw.edu. including peak cone density, rod-free zone diameter, and Henle fiber layer. (Invest Ophthalmol Vis Sci. 2012;53:1628-1636) DOI:10.1167/iovs.11-8488

$T$ he macula is a highly specialized region of the human retina, characterized by the foveal avascular zone (FAZ), complete excavation of inner retinal neurons (creating the characteristic fovea, or pit), increased cone packing, and an absence of rod photoreceptors. ${ }^{1}$ Although the fovea itself represents a small area of the retina, it drives the majority of our visual function. ${ }^{2}$ Characterization of the foveal region in healthy and diseased retina is of great interest, specifically with regard to development and aging. Disrupted foveal development is associated with diseases such as retinopathy of prematurity $^{3-6}$ and albinism. ${ }^{7-12}$ Various aspects of foveal anatomy are also altered in retinal diseases, such as diabetic retinopathy ${ }^{13-15}$ and age-related macular degeneration. ${ }^{16}$ Constructing accurate models of foveal development and discriminating pathologic foveal alterations from normal age-related changes requires, in part, a clear understanding of the relationship between the various anatomic specializations associated with the foveal region in both the healthy and the diseased retina.

Two features of the foveal region that have been linked during development are the pit and the FAZ, and there are conflicting hypotheses accounting for their developmental relatedness. ${ }^{2,17}$ The data that had been used to construct these models of foveal development have been based largely on relatively limited anatomic data. Although this enables coordinated examination of tissue from very early in development, this approach does not allow routine access to samples from patients with altered foveal morphology or the construction of robust normative databases. Emerging advances in ophthalmic imaging permit direct in vivo visualization of all anatomic specializations of the foveal region. These imaging tools offer the opportunity to examine foveal anatomy in a more diverse population as well as in patients with altered foveal development so as to enable robust testing of predictions made by existing models of foveal development.

Equally significant is improving our understanding of how the anatomy of the foveal region changes with age so as to improve the sensitivity of in vivo imaging tools for detecting pathology. Current data are conflicting with regard to the presence of significant age-related changes in foveal anatomy due, in part, to the tremendous variation in these structures but also to the fact that most previous studies have only examined a single parameter in isolation as opposed to multiple anatomic features at the same time. For example, it has been suggested that macular pigment density increases with age ${ }^{18-20}$ though this has not been observed in all studies. ${ }^{21,22}$ Similarly, data suggest that cone density decreases with age, ${ }^{23,24}$ but other data are consistent with no significant change with age. ${ }^{25,26}$ Isolated reports suggest that the radius of curvature of the foveal pit decreases with age, ${ }^{27}$ though a recent optical coherence tomography (OCT) study found no change in foveal pit 
morphology with age. ${ }^{28}$ The size of the FAZ has been reported to increase with age, ${ }^{29,30}$ as has the thickness of the Henle fiber layer. $^{31}$

OCT allows three-dimensional volumetric imaging of the macula, which permits direct visualization of the foveal pit. Numerous studies have reported on the morphology of the foveal pit in the healthy retina, ${ }^{28,32-35}$ demonstrating remarkable interindividual variation in pit morphology. The FAZ has also been well studied and can be visualized using a variety of techniques including entoptic viewing, ${ }^{36-38}$ fluorescein (FA) ${ }^{39}$ histologic techniques, ${ }^{40}$ and, more recently, high-resolution imaging tools such as OCT, ${ }^{41,42}$ adaptive optics (AO) scanning laser ophthalmoscopy, ${ }^{43}$ and flood-illuminated AO ophthalmoscopy. ${ }^{44}$ Collectively from these techniques, it is becoming appreciated that the size of the FAZ is highly variable, though the variability of both the foveal pit and the FAZ must be explained within the context of current models of foveal development.

Correlations between FAZ size and foveal pit morphology have been reported. For example, patients with a history of retinopathy of prematurity (ROP) have smaller foveal pits coupled with a smaller or even an absent FAZ. ${ }^{5}$ In addition, patients with albinism are known to lack a FAZ and to have pronounced foveal hypoplasia. ${ }^{11,12,45}$ A recent study on a small number of healthy subjects showed that larger foveal pits were associated with a larger FAZ, although this was performed in patients with unilateral retinal disease, so it is unclear how representative this is of a truly normal population. ${ }^{28}$ Additionally, the lateral scale of the OCT and FAZ images were not corrected for differences in ocular magnification because of individual differences in axial length. Here, using multiple in vivo retinal imaging tools and image processing techniques, we sought to assess the relationship between FAZ size and foveal pit morphology in a larger normative population. These data provide a foundation with which to explore other anatomic aspects of the foveal region, such as the topography of the cone and rod photoreceptor mosaic, which is now fully accessible with AO imaging tools. ${ }^{46,47}$ Such comprehensive data could then be used to test predictions of competing models of foveal development.

\section{Methods}

\section{Human Subjects}

All research on human subjects followed the tenets of the Declaration of Helsinki and was approved by Institutional Review Board at the Medical College of Wisconsin. Informed consent was obtained from all subjects after explanation of the nature and possible consequences of the study. Forty-two subjects ( 26 men, 16 women) aged 18 years and older (average, 26.5 years; range, 18-67 years) were recruited from local communities surrounding the Medical College of Wisconsin. Thirty-three of the subjects were Caucasian, seven were Asian Indians, and two were African Americans. For the imaging experiments, one eye was dilated in each subject, and accommodation was suspended using one drop each of phenylephrine hydrochloride (2.5\%) and tropicamide (1\%). Subjects were allowed to choose which eye was imaged (31 of 42 were right eyes). In all subjects, axial length was measured using an interferometer (IOL Master; Carl Zeiss Meditec, Dublin, CA). For comparison, data from a patient previously diagnosed with albinism and foveal hypoplasia was included for comparison against the healthy exemplars (Carroll J, et al. IOVS 2011;52:ARVO E-Abstract 2175).

\section{Optical Coherence Tomography}

Volumetric images of the macula were obtained using spectral domain OCT (Cirrus HD-OCT; Carl Zeiss Meditec). Volumes were nominally 6 $\mathrm{mm} \times 6 \mathrm{~mm}$ and consisted of 128 B-scans (512 A-scans/B-scan). The internal fixation target of the system-a large green asterisk on a red background-was used. Focus of the fundus image was optimized using built-in focus correction, and the polarization setting was optimized using the built-in function. Retinal thickness data from the macular volume scans and the location of center of the foveal pit was exported (Cirrus Research Browser 5.0; Carl Zeiss Meditec).

\section{FAZ Imaging}

The FAZ was imaged in each subject using at least 1 of 2 devices. The first was used to image 33 subjects and is a modified fundus camera using $548 \mathrm{~nm}$ light to illuminate a $20^{\circ}$ field of view (Retinal Function Imager [RFI]; Optical Imaging Ltd., Rehovat, Israel). ${ }^{48}$ RFI proprietary motion contrast-enhancing software was used for blood vessel enhancement. A single image set consisted of eight images taken over $250 \mathrm{~ms}$. At least eight, but not more than 18, image sets were taken and registered using the RFI software.

The second device to image the FAZ in 11 subjects was a newly constructed AO scanning light ophthalmoscope (AOSLO). ${ }^{49}$ Images were acquired using a 775-nm superluminescent diode with a fullwidth half-maximum bandwidth of $13.8 \mathrm{~nm}$ (InPhenix, Livermore, CA). The scanning beam subtends a $0.96^{\circ} \times 0.96^{\circ}$ area on the retina. The plane of focus was set at the inner retina to capture reflected light from the capillaries defining the FAZ (Burns SA, et al. IOVS 2008; 49 :ARVO E-Abstract 4512). Nine imaging locations were sampled to cover the entire FAZ, with subjects instructed to fixate at different locations on the scanning beam (each corner, middle of each edge, and center). Additional imaging locations were sampled in subjects with larger FAZs by instructing them to fixate away from the scanning beam until the FAZ capillaries were visible. In these subjects, as many as 15 different imaging locations were required to cover the entire FAZ. In all subjects, a single image sequence consisting of 150 frames was acquired at each imaging location.

To correct for distortions in the retinal images caused by the sinusoidal motion of the resonant optical scanner, we first estimated the distortion from images of a Ronchi ruling and then resampled the retinal images over a grid of equally spaced pixels. After this desinusoiding, the image sequences were manually inspected to identify reference frame or frames with minimal distortion and maximal sharpness for subsequent registration. Registration of frames within a given image sequence was performed using a rigid translation method in which each frame was aligned to the reference frame by maximizing the normalized cross-correlation function between them. ${ }^{50}$ Once all the frames were registered, the 40 frames with the highest normalized cross-correlation to the reference frame were averaged to generate a final image with an increased signal-to-noise ratio for subsequent analysis. The averaged images were then montaged using commercial software (Photoshop; Adobe Systems, San Jose, CA). Auto-leveling was used to minimize differences in brightness and contrast between images before montaging. No additional processing was applied to the AOSLO images.

Two subjects were also imaged using conventional FA performed with a commercial SLO system (Heidelberg Spectralis HRA+OCT; Heidelberg Engineering, Heidelberg, Germany). The system was set to a $20^{\circ}$ field of view, and onboard image registration was used to acquire 14 frames, which were then averaged. These two subjects were imaged using both RFI and AOSLO. This was done to examine the interchangeable use of the RFI and AOLSO for visualizing the FAZ and to compare both noninvasive techniques with the current gold standard (FA).

\section{FAZ Quantification}

Regardless of the method of acquisition, the size of the FAZ was assessed the same way for all images. The FAZ area was measured using a custom semiautomated segmentation algorithm (Matlab; Mathworks, Natick, MA), based on previously published level-set algorithms. ${ }^{39,43}$ Figure 1A shows a sample FAZ image acquired with the RFI. Edge points were manually selected along the centerline of the vessels 

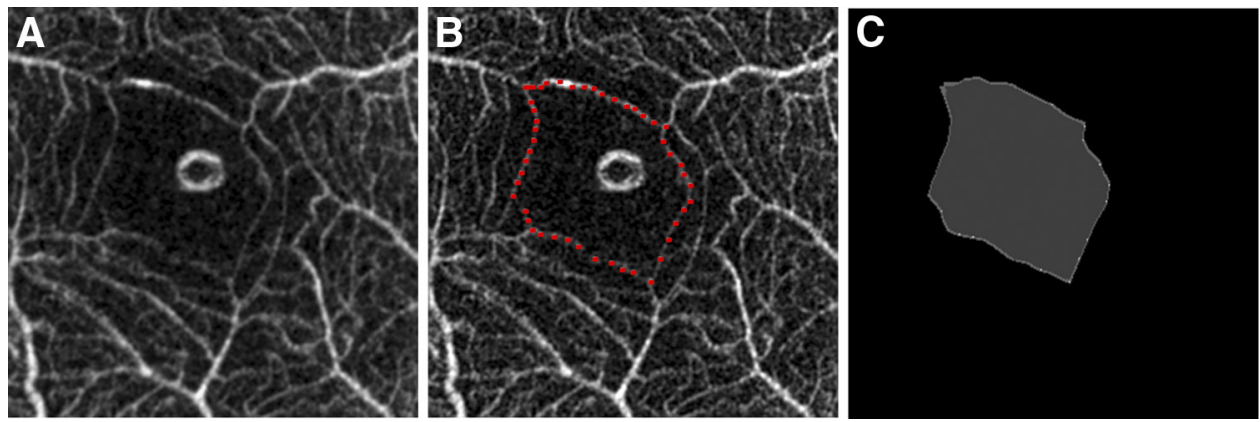

FIGURE 1. Quantifying FAZ morphology using semiautomated segmentation methods. (A) FAZ image from subject JC_0342 taken with the RFI. (B) The edge of the FAZ was delineated with 40 manually selected points. (C) The coordinates were saved and processed with custom software to quantify FAZ area.

bordering the FAZ using ImageJ software (a publicly available image processing program developed by Wayne Rasband, National Institutes of Health, Bethesda, MD; available at http://rsb.info.nih.gov/ij/index. html). ${ }^{51}$ An example of a manually selected FAZ boundary is shown in Figure 1B. Linear interpolation was performed between consecutive selected coordinates to generate a closed contour defining the FAZ (Fig. 1C, filled area). From this contour, estimates of FAZ area and diameter were derived. To compute the area, a seed point at the center of the closed contour was defined by calculating the center of mass of the $(x, y)$ coordinates defining the contour. This seed point was used as the starting point of a flooding algorithm in the custom semiautomated segmentation algorithm (Matlab; Mathworks), which was used to define all pixels that reside within the closed contour. The area of the FAZ was computed by multiplying the number of pixels within the contour by the area of a single pixel. The area of a single pixel is estimated using the image scale (deg/pixel) and that subject's retinal magnification $(\mathrm{mm} / \mathrm{deg})$, calculated using linear scaling based on 0.291 $\mathrm{mm} / \mathrm{deg}$ for 24-mm axial length

To estimate FAZ diameter, 180 radial lines at $1^{\circ}$ increments were placed at the central seed point, and their lengths were adjusted until each contacted the edge of the closed contour line. The average length of these 180 lines was taken as the diameter of the FAZ, with the distance in pixels converted to millimeters using a similar linear conversion described for FAZ area. The number and increment of these radial lines was chosen to resemble sampling used to assess foveal pit morphology. Finally, as the segmentation method involved significant user input, two observers segmented all images. The agreement between the FAZ area estimates derived from the segmentation data of the two observers is shown in Figure 2. The mean difference is 0.029 $\mathrm{mm}^{2}\left(95 \%\right.$ confidence interval $\left.[\mathrm{CI}], 0.016-0.041 \mathrm{~mm}^{2}\right)$, indicating a slight bias of one observer to select a larger FAZ segmentation. The limits of agreement are $-0.05 \mathrm{~mm}^{2}$ and $0.11 \mathrm{~mm}^{2}$. For the subsequent analyses, the FAZ area value used was the average of the values obtained from the two observers. Because FAZ area and diameter are highly correlated (Supplementary Fig. S1, http://www.iovs.org/ lookup/suppl/doi:10.1167/iovs.11-8488/-/DCSupplemental), they can be considered equivalent variables. Thus, only one of them (FAZ area) was compared against foveal pit morphology.

\section{Foveal Pit Metrics}

To improve the accuracy of the foveal pit measurements, the lateral scale of all retinal thickness data sets was corrected for interindividual differences in axial length. To derive the actual scan lengths, we multiplied $6 \mathrm{~mm}$ (the nominal scan length) by the ratio of the subject's actual axial length to that assumed by the instrument $(24.46 \mathrm{~mm})$. Foveal pit morphology was assessed using a modified version of a previously published algorithm. ${ }^{33}$ From exported retinal thickness data, 180 radially oriented slices through the foveal center were extracted (by necessity, using interpolated data points). The foveal center was defined using an automated algorithm (Foveal Finder) onboard the spectral domain OCT (Cirrus HD-OCT; Carl Zeiss Meditec) system. Each of these thickness profiles was then fit to a difference of Gaussians (DoG). The first derivative of the best-fitting DoG provides information about the changing slope of the foveal contour and allows automated and objective extraction of foveal pit depth, diameter, and slope. The center of the foveal pit is identified as the central retinal location where the slope is zero. Moving away from the foveal center, the rim of the foveal pit is also identified as a location of zero slopes. Diameter was defined as the rim-to-rim distance, and depth from a given thickness profile was taken as the difference between the average retinal thickness at the two rim locations and the thickness at the foveal pit. The maximum slope value between the foveal center and the foveal rim was recorded as the foveal slope parameter.

In addition to depth and diameter, we examined foveal pit volume Here we defined foveal pit volume as the fill of the foveal pit, that is, the space between the internal limiting membrane surface and the top of the foveal pit. Again, the center of the foveal pit was identified within each macular thickness data set (Fig. 3A) using the automated algorithm (Foveal Finder) onboard the spectral domain OCT (Cirrus HD-OCT; Carl Zeiss Meditec) system. The rim of the entire foveal pit was defined using the rim locations determined from the DoG-fitting procedure described (Fig. 3B), and the 360 thickness values were used as the edges of a contour to be used for the foveal pit volume calculation. As the retinal thickness data are sampled more finely along the horizontal direction (512 A-scans) than the vertical direction (128 B-scans), we scanned a vertical line across the thickness volume that connected the superior and inferior rim locations at each of the 512

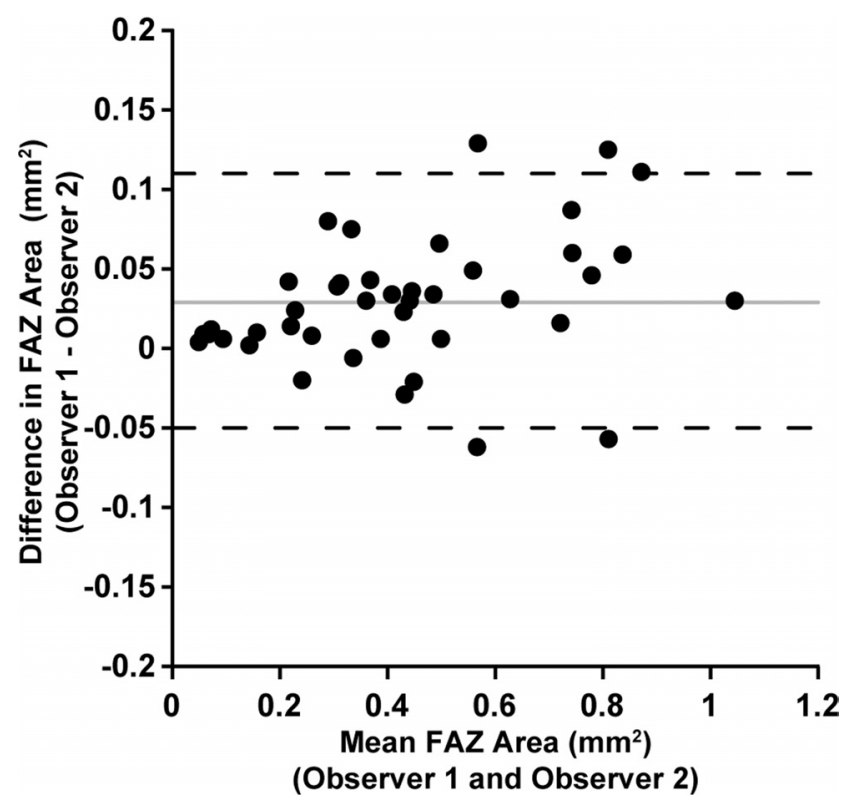

Figure 2. Bland-Altman plot showing the agreement between FAZ area values obtained from manual segmentation data performed by two observers. The mean difference is $0.029 \mathrm{~mm}^{2}$ (95\% CI, 0.016-0.041 $\mathrm{mm}^{2}$ ), indicating a slight bias of one observer to select a larger FAZ segmentation. The limits of agreement are $-0.05 \mathrm{~mm}^{2}$ and $0.11 \mathrm{~mm}^{2}$. For subsequent analyses, the FAZ area value used is the average of the values obtained from the two observers. 
Figure 3. Process for measuring foveal pit volume. (A) Retinal thickness maps were exported and interpolated to $512 \times 512$ pixels and then transformed to polar coordinates. (B) The foveal rim was defined as described in the text. An irregular surface was defined as described in the text to create a cap on the foveal pit. (C) The fill of the space between this cap and the internal limiting membrane represents the volume of the foveal pit.

\section{A}

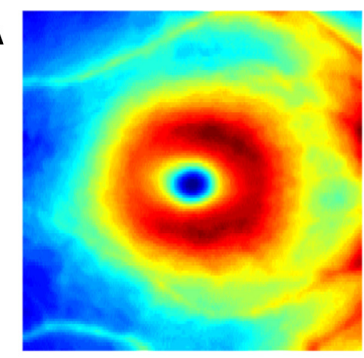

B

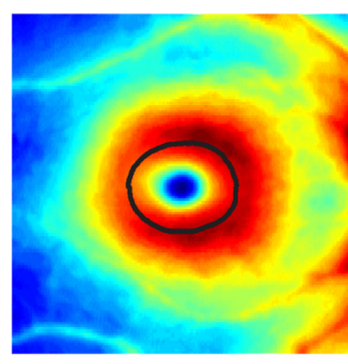

180

$\begin{array}{lll}240 & 300 & 360\end{array}$
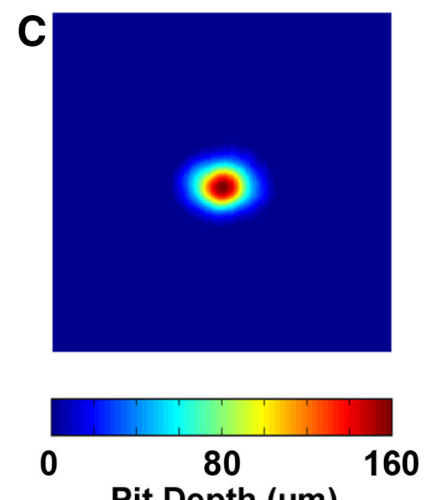

Pit Depth $(\mu \mathrm{m})$

A-scan positions. Collectively, these lines defined an irregular surface that was then used for the foveal pit volume calculation. The surface captures the nasal-temporal and superior-inferior asymmetries in the rim contour. The difference between this surface and the actual retinal thickness at all the points confined within the rim contour (outlined in Fig. 3B) is shown in Figure 3C as pit depth values. By definition, the pit has no depth outside the rim contour; hence, these pixels have a value of zero. To derive an estimate of foveal pit volume, the pit depth values were summed and multiplied by the area over which they were sampled (defined by the rim contour).

Foveal pit area was calculated using the same contour in Figure 3B, to which a flooding algorithm such as that described for the FAZ was applied. Foveal pit area and diameter are highly correlated (Supplementary Fig. S1, http://www.iovs.org/lookup/suppl/doi:10.1167/iovs. 11-8488/-/DCSupplemental) and can thus be considered equivalent variables; as such, only one of them (foveal pit area) was compared against FAZ area.

\section{Statistical Analysis}

The relationship between foveal pit morphology and FAZ was analyzed using simple, partial, and multiple Spearman's correlation, as specified. Given that four descriptors of foveal pit morphology were considered, a Bonferroni-adjusted $1.25 \%$ significance level was used to claim statistical significance. With 42 subjects, our study had $80 \%$ power to detect correlations with $\rho^{2}$ of 0.24 or above at a $1.25 \%$ two-sided significance level. All analyses were performed using R, version 2.13.1 (R Foundation for Statistical Computing, Vienna, Austria).

\section{Results}

\section{Assessing FAZ Morphology}

The FAZ area was variable in our population, ranging from 0.05 to $1.05 \mathrm{~mm}^{2}$. The average $\pm \mathrm{SD}$ for the population was $0.43 \pm$ $0.25 \mathrm{~mm}^{2}$. The average FAZ diameter was $0.66 \pm 0.22 \mathrm{~mm}$, with a range of 0.20 to $1.08 \mathrm{~mm}$. Because of the availability of different imaging modalities during the period of data collection, we examined the interchangeability of FAZ parameters derived from two different imaging devices (RFI and AOSLO) for two subjects. We also imaged these same two subjects with conventional FA to see how our noninvasive images compared with the current clinical gold standard. Although vessel width and contrast vary between images obtained on the three in struments, the smallest capillaries appear to be visible in all images (Fig. 4). This is demonstrated by the good correspondence in FAZ metrics derived for each subject from images on the three instruments. For example, FAZ area was $0.31,0.30$, and $0.29 \mathrm{~mm}^{2}$ (subject JC_0002) and $0.09,0.10$, and $0.09 \mathrm{~mm}^{2}$ (subject JC_0007) for the RFI, AOSLO, and FA images, respectively.

\section{Foveal Pit Morphology}

In our 42 subjects, foveal pit depth varied by more than threefold (range, $0.048-0.156 \mathrm{~mm}$ ); there was a twofold variability in foveal diameter (range, $1.12-2.40 \mathrm{~mm}$ ) and more than a fourfold variation in foveal slope (range, $5.1^{\circ}-21.0^{\circ}$ ). Previous work from our laboratory showed that depth and diameter of the foveal pit were not correlated, ${ }^{35}$ and they were not significantly correlated in the present study $\left(\rho^{2}=0.07 ; P=\right.$ 0.08 ). Neither metric alone completely captures the entire morphology of the foveal pit. Foveal pit volume is influenced by both depth and diameter and, therefore, may be a useful metric for examining how overall pit morphology correlates with other anatomic aspects of foveal specialization. We observed a more than eightfold variation in foveal pit volume (range, $0.022-0.190 \mathrm{~mm}^{3}$ ). The area of the foveal pit varied by more than fourfold (range, $1.00-4.54 \mathrm{~mm}^{2}$ ). A complete listing of all FAZ and foveal pit metrics for our 42 subjects is given in Table 1.

\section{Correlation of FAZ Size and Foveal Pit Morphology}

FAZ area was strongly correlated with pit area $\left(\rho^{2}=0.33 ; P<\right.$ $0.0001)$ and pit depth $\left(\rho^{2}=0.29 ; P=0.0002\right)$, with the deepest and widest foveal pits found in subjects with the largest FAZs (Figs. 5A, 5B). These correlations persist even after adjusting for the other characteristic. The partial correlations of FAZ area with pit area adjusted for pit depth $\left(\rho^{2}=0.27 ; P=\right.$ 0.00014 ) and of FAZ area with pit depth adjusted for pit area
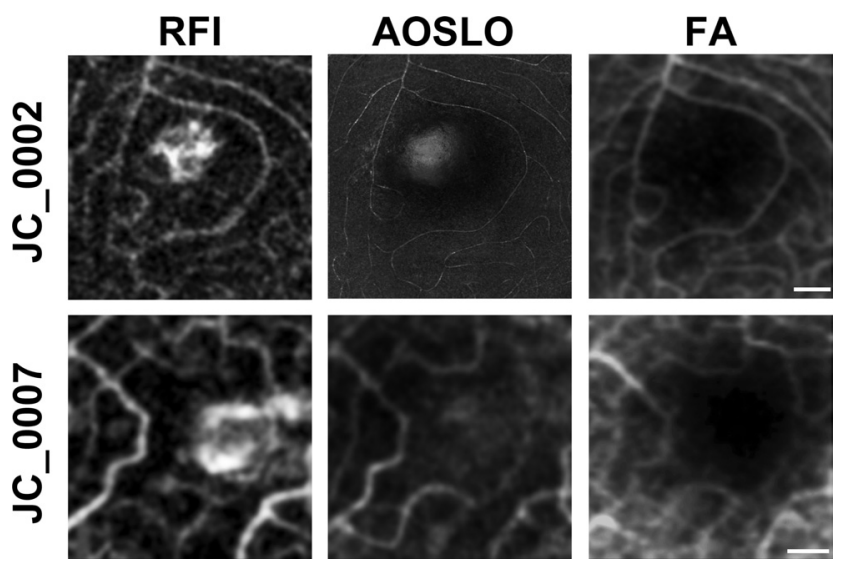

FIGURE 4. Comparison of FAZ imaging methods. Shown are images of the FAZ for two subjects obtained using three different imaging methods (RFI, AOSLO, FA). Estimates of FAZ area varied by $<1.5 \%$ between the three methods for each subject. Scale bars, $0.10 \mathrm{~mm}$. 
TABLe 1. FAZ and Foveal Pit Data

\begin{tabular}{|c|c|c|c|c|c|c|c|c|c|c|}
\hline \multirow[b]{2}{*}{ ID } & \multirow[b]{2}{*}{ Sex } & \multirow[b]{2}{*}{ Age } & \multirow[b]{2}{*}{$\begin{array}{l}\text { Axial Length } \\
\text { (mm)* }\end{array}$} & \multicolumn{2}{|c|}{ FAZ Metrics } & \multicolumn{5}{|c|}{ Foveal Pit Metrics } \\
\hline & & & & $\begin{array}{l}\text { Diameter } \\
\text { (mm) }\end{array}$ & $\begin{array}{c}\text { Area } \\
\left(\mathrm{mm}^{2}\right) \dagger\end{array}$ & $\begin{array}{l}\text { Depth } \\
\text { (mm) }\end{array}$ & $\begin{array}{l}\text { Diameter } \\
\text { (mm) }\end{array}$ & $\begin{array}{l}\text { Slope } \\
\text { (deg) }\end{array}$ & $\begin{array}{l}\text { Volume } \\
\left(\mathrm{mm}^{3}\right)\end{array}$ & $\begin{array}{c}\text { Area } \\
\left(\mathrm{mm}^{2}\right)\end{array}$ \\
\hline JC_0002 & $\mathbf{M}$ & 26 & 24.71 & 0.57 & $0.31 \neq$ & 0.102 & 1.84 & 11.4 & 0.065 & 2.67 \\
\hline JC_0003 & $\mathrm{F}$ & 29 & 24.35 & 0.20 & 0.068 & 0.058 & 1.79 & 6.0 & 0.040 & 2.54 \\
\hline JC_0007 & M & 35 & $27.37^{*}$ & 0.40 & $0.09 \ddagger$ & 0.056 & 1.93 & 5.5 & 0.025 & 2.81 \\
\hline JC_0138 & $\mathrm{F}$ & 26 & 22.75 & 0.95 & 0.78 & 0.113 & 2.26 & 9.8 & 0.136 & 4.49 \\
\hline JC_0200 & $\mathbf{M}$ & 23 & 24.72 & 0.69 & 0.43 & 0.138 & 1.75 & 15.3 & 0.084 & 2.43 \\
\hline JC_0209 & M & 23 & $24.29^{*}$ & 0.63 & 0.37 & 0.118 & 1.93 & 11.9 & 0.089 & 2.94 \\
\hline JC_0232 & M & 31 & 26.35 & 0.59 & 0.34 & 0.117 & 1.63 & 14.0 & 0.053 & 2.11 \\
\hline JC_0241 & $\mathbf{M}$ & 25 & 25.66 & 0.55 & 0.29 & 0.153 & 1.57 & 19.2 & 0.059 & 1.93 \\
\hline JC_0342 & M & 24 & 23.67 & 0.66 & 0.41 & 0.128 & 1.82 & 14.0 & 0.088 & 2.61 \\
\hline JC_0343 & $\mathbf{M}$ & 25 & 23.29 & 0.95 & 0.74 & 0.122 & 2.00 & 11.9 & 0.100 & 3.14 \\
\hline JC_0363 & $\mathrm{F}$ & 21 & 23.53 & 0.60 & 0.33 & 0.084 & 1.71 & 9.5 & 0.051 & 2.31 \\
\hline JC_0364 & $\mathbf{M}$ & 21 & 23.41 & 0.65 & 0.39 & 0.135 & 1.69 & 15.7 & 0.072 & 2.26 \\
\hline JC_0365 & $\mathbf{M}$ & 20 & 23.79 & 0.96 & 0.81 & 0.153 & 2.05 & 14.4 & 0.126 & 3.32 \\
\hline JC_0383 & $\mathbf{M}$ & 18 & $24.67^{*}$ & 0.74 & 0.50 & 0.101 & 1.97 & 9.9 & 0.084 & 3.05 \\
\hline JC_0384 & $\mathrm{F}$ & 27 & 22.78 & 0.80 & 0.56 & 0.139 & 1.77 & 15.5 & 0.083 & 2.46 \\
\hline JC_0385 & $\mathbf{M}$ & 31 & $22.77^{*}$ & 0.90 & 0.72 & 0.140 & 2.40 & 11.2 & 0.190 & 4.54 \\
\hline JC_0387 & $\mathbf{M}$ & 22 & 23.56 & 0.83 & 0.63 & 0.130 & 1.95 & 13.3 & 0.102 & 2.99 \\
\hline JC_0391 & M & 21 & $25.90^{*}$ & 1.08 & 1.05 & 0.156 & 2.16 & 14.1 & 0.126 & 3.66 \\
\hline JC_0392 & $\mathbf{M}$ & 21 & $23.54^{*}$ & 0.73 & 0.49 & 0.112 & 2.26 & 9.3 & 0.135 & 4.16 \\
\hline JC_0394 & $\mathrm{F}$ & 21 & 24.62 & 0.69 & 0.44 & 0.107 & 1.59 & 13.1 & 0.050 & 1.99 \\
\hline JC_0395 & M & 22 & 23.73 & 0.69 & 0.43 & 0.144 & 1.79 & 15.6 & 0.098 & 2.55 \\
\hline JC_0398 & $\mathrm{F}$ & 21 & 24.47 & 0.62 & 0.36 & 0.125 & 1.80 & 13.9 & 0.073 & 2.53 \\
\hline JC_0399 & $\mathrm{F}$ & 22 & $23.57^{*}$ & 0.70 & 0.45 & 0.130 & 1.78 & 15.5 & 0.085 & 2.50 \\
\hline JC_0410 & $\mathbf{M}$ & 20 & 24.05 & 0.99 & 0.84 & 0.145 & 2.00 & 14.0 & 0.111 & 3.16 \\
\hline JC_0412 & $\mathrm{F}$ & 21 & $22.24^{*}$ & 0.71 & 0.57 & 0.125 & 1.85 & 13.5 & 0.090 & 2.71 \\
\hline JC_0414 & $\mathrm{F}$ & 22 & 23.28 & 0.80 & 0.57 & 0.118 & 2.08 & 10.6 & 0.109 & 3.74 \\
\hline JC_0416 & $\mathrm{F}$ & 19 & 25.15 & 0.92 & 0.74 & 0.084 & 2.12 & 8.2 & 0.078 & 3.08 \\
\hline JC_0420 & $\mathrm{F}$ & 21 & $22.86^{*}$ & 0.24 & 0.07 & 0.084 & 1.59 & 10.1 & 0.046 & 1.99 \\
\hline JC_0424 & $\mathbf{M}$ & 26 & $23.00^{*}$ & 0.99 & 0.87 & 0.146 & 2.00 & 14.1 & 0.120 & 3.15 \\
\hline JC_0571 & $\mathbf{M}$ & 25 & 24.05 & 0.41 & 0.140 & 0.117 & 1.77 & 13.1 & 0.071 & 2.49 \\
\hline JC_0616 & M & 23 & 24.35 & 0.52 & 0.228 & 0.129 & 1.94 & 12.7 & 0.107 & 2.98 \\
\hline JC_0628 & M & 63 & 22.92 & 0.26 & $0.07 \delta$ & 0.048 & 1.71 & 5.1 & 0.023 & 2.44 \\
\hline JC_0629 & $\mathrm{F}$ & 67 & 23.29 & 0.50 & 0.228 & 0.103 & 1.68 & 11.9 & 0.058 & 2.23 \\
\hline JC_0645 & $\mathbf{M}$ & 21 & 23.76 & 0.54 & 0.260 & 0.146 & 2.01 & 14.4 & 0.117 & 3.17 \\
\hline JC_0654 & $\mathrm{F}$ & 25 & 23.57 & 0.40 & 0.168 & 0.093 & 1.82 & 10.6 & 0.057 & 2.61 \\
\hline JC_0661 & $\mathbf{M}$ & 23 & 25.52 & 0.57 & 0.240 & 0.125 & 1.61 & 15.7 & 0.056 & 2.05 \\
\hline JC_0677 & $\mathrm{F}$ & 22 & 24.03 & 0.79 & $0.50 \$$ & 0.134 & 2.00 & 13.0 & 0.107 & 3.16 \\
\hline JC_0691 & $\mathrm{F}$ & 42 & 26.27 & 0.95 & 0.81 & 0.119 & 1.87 & 12.3 & 0.071 & 2.75 \\
\hline JC_0692 & $\mathbf{M}$ & 39 & 24.54 & 0.70 & 0.45 & 0.104 & 1.50 & 13.8 & 0.041 & 1.78 \\
\hline JC_0693 & $\mathbf{M}$ & 28 & 24.10 & 0.48 & 0.23 & 0.106 & 1.89 & 11.3 & 0.069 & 2.81 \\
\hline JC_0694 & $\mathrm{F}$ & 22 & 23.90 & 0.56 & 0.31 & 0.117 & 1.12 & 21.0 & 0.022 & 1.00 \\
\hline JC_0695 & $\mathbf{M}$ & 28 & $23.37^{*}$ & 0.27 & 0.05 & 0.081 & 1.73 & 8.4 & 0.057 & 2.37 \\
\hline Average & & 26 & 24.08 & 0.66 & 0.43 & 0.116 & 1.85 & 12.5 & 0.081 & 2.75 \\
\hline SD & & 10 & 1.09 & 0.22 & 0.25 & 0.026 & 0.23 & 3.2 & 0.035 & 0.69 \\
\hline
\end{tabular}

* In all but 11 subjects, data reported are for right eyes.

† FAZ imaged with RFI, except for two patients imaged with RFI, AOSLO, and conventional FA ( $)$ ), and nine patients imaged with AOSLO only ( $§$ ).

$\left(\rho^{2}=0.23 ; P=0.00075\right)$ are similar to the unadjusted correlations, suggesting that the contributions of foveal pit depth and foveal pit area are independent and approximately equal. This is confirmed by the fact that the multiple squared corre- lation of foveal pit depth and foveal pit area with FAZ area is essentially the sum of the individual contributions $\left(\rho^{2}=0.48\right.$; $P<0.0001$ ). Our subjects did subtend a large range of ages; however, adjustment of the multiple correlation estimate for
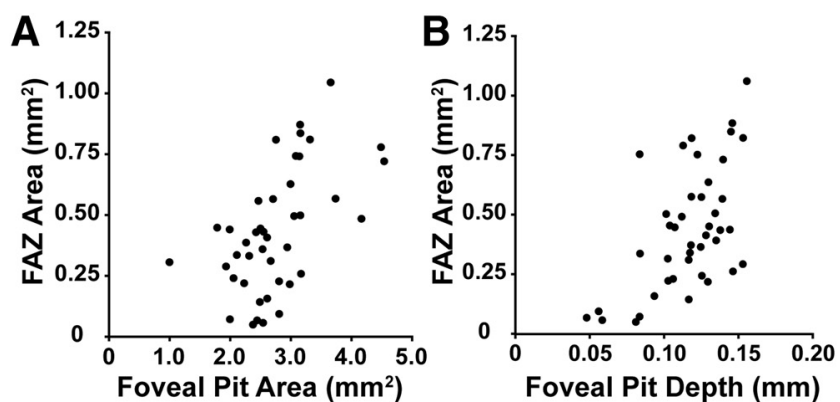

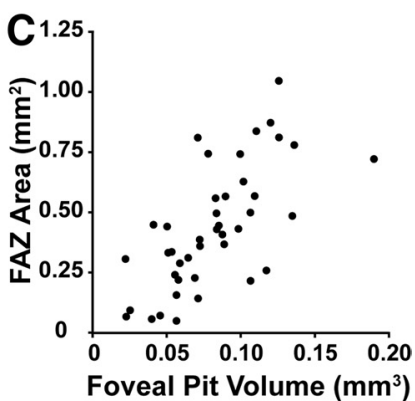

FiguRE 5. Correlation between FAZ area and foveal pit morphology. Significant correlation between FAZ area and foveal pit area (A), pit depth (B), and pit volume (C) were observed. Collectively, these data indicate that bigger FAZs are associated with larger foveal pits, which is consistent with the hypothesis that the size of the FAZ determines the degree of foveal excavation. 
age does not modify it $\left(\rho^{2}=0.49 ; P=0.77\right.$ for additional effect of age). As shown in Figure 5C, FAZ area is also correlated with pit volume $\left(\rho^{2}=0.46 ; P<0.0001\right)$, which is expected because volume is a monotone combination of depth and area. There was no significant correlation between axial length and either FAZ area $\left(\rho^{2}=0.0098 ; P=0.53\right)$ or foveal pit area $\left(\rho^{2}=0.029\right.$; $P=0.27)$.

Further visualization of the relationship between the FAZ and the foveal pit can be seen in Figure 6. Here we show the vasculature map and macular thickness map of a patient with albinism. In this patient, there is an absence of a defined avascular zone at the location of fixation, coupled with an absence of a foveal pit. Also shown are images from two subjects with foveal pit morphology near the extremes of our sample, highlighting, the quantitative relationship defined in Figure 5; subjects with larger foveal pits have larger FAZs.

\section{Discussion}

\section{Comparison with Previous Data on Foveal Pit Morphology}

Numerous in vitro studies have examined foveal pit morphology. ${ }^{2,17,52-55}$ It is difficult to find reference to any major variability in this structure from these studies, probably because of the relatively small number of retinas examined. However, with the advent of noninvasive OCT imaging, foveal pit morphology is routinely accessible in vivo and has been extensively reexamined both in healthy and in diseased eyes. ${ }^{5,12,28,33,35,56,57}$ Importantly, studies such as these have enabled a quantitative analysis of the disruption of foveal pit morphology in retinal diseases such as retinopathy of prematurity and albinism, which previously had only been qualitatively described as foveal hypoplasia or foveal plana. ${ }^{45}$ Foveal pit morphology may also be of use in studying the retinal effects of neurologic conditions such as Parkinson disease (Bodis-Wollner IG, et al. IOVS 2011;52:ARVO E-Abstract 6660).

One of the difficulties in making detailed comparisons of pit morphology across normative data from different studies is the variation in metrics used to describe the foveal pit. Published metrics include pit depth (typically defined as the distance from the base of the foveal pit to a plane connecting the overlying foveal rim, or from the base to the level at which the pit reaches a lateral radius of $728 \mu \mathrm{m}$ ), width/diameter (defined as either the subjective or the objective rim-to-rim diameter or width of the region in which a nerve fiber layer is absent), slope (defined as either the average or the maximum slope between the foveal center and the rim of the foveal pit), and foveal inner retinal area (cross-sectional area of the inner retinal tissue within $500 \mu \mathrm{m}$ from the foveal center, bordered by the fovea, the internal limiting membrane, and the outer plexiform layer). ${ }^{5,28,32,34,35}$ We have introduced here foveal pit volume because it captures multiple aspects of pit morphology in a single metric. This may prove useful in trying to examine the relationship between foveal morphology and other structural or functional measures of the visual system. However, the independence of pit depth and diameter suggests that any single metric (including foveal pit volume) may be of limited use for modeling foveal pit development. There are additional complications in comparing the present study with previous studies; we corrected our measurements for individual variations in axial length. This would affect any transverse measurements (pit diameter, pit area) but would minimally affect pit depth. That said, the different metrics used to describe the pit present a much larger impediment to comparisons between previous studies and the present study than do differences in transverse magnification.

In the face of these varied metrics to describe the foveal pit, there remains a need for convergence on some objective definitions of foveal pit morphology. This would permit easier comparison across studies and could aid in the development of normative databases of foveal morphology. Combining this and previous studies, we have now accumulated foveal pit data on 180 subjects with normal vision using the same foveal pit metrics. ${ }^{33,35}$ Variation in foveal pit morphology certainly exceeds that appreciated from earlier histologic studies. For example, foveal pit diameter varies by more than a factor of 2 (range, $1.12-2.57 \mathrm{~mm}$ ), and foveal pit depth varies by at least a factor of 5.5 (range, $0.032-0.176 \mathrm{~mm}$ ). Given that we have obtained data from multiple racial/ethnic groups and both sexes, we suspect that our data set represents nearly the entire range of normal pit morphology.

\section{Functional Significance of the Fovea}

In both the healthy and the diseased retina, the functional significance of variability in foveal pit morphology remains unclear. The overall impression is that a fovea is required for good vision, based on the fact that patients with foveal hypoplasia (ROP, albinism, aniridia) have reduced vision. But is the fovea (i.e., the pit) the culprit? Recent work ${ }^{57}$ has shown that across various forms of typical foveal hypoplasia, patients with more shallow foveal pits had worse acuity than those with more pronounced foveal pits, which would seem to support the idea that the pit itself is required for good vision. In fact, Walls ${ }^{58}$ proposed that the presence of a fovea might serve a refractive role by locally magnifying the retinal image onto the foveal cone mosaic. Evidence against this comes from the
FIGURE 6. Examples of increasing FAZ with increasing foveal pit excavation. Foveal OCT scans $(\mathbf{A}, \mathbf{D}, \mathbf{G})$, retinal thickness maps $(\mathbf{B}, \mathbf{E}, \mathbf{H})$, and FAZ images $(\mathbf{C}, \mathbf{F}, \mathbf{I})$ are shown for three subjects. Data from the left eye of a patient with albinism reveals that the absence of a foveal pit is associated with the absence of a FAZ (A-C). The data from this patient were not included in the present analysis but is shown to illustrate one extreme in how the FAZ and pit are related. In two healthy persons with extreme foveal pit morphology, the positive correlation between the size of the foveal pit and the size of the FAZ is captured (D-I). Scale bar, $100 \mu \mathrm{m}$.
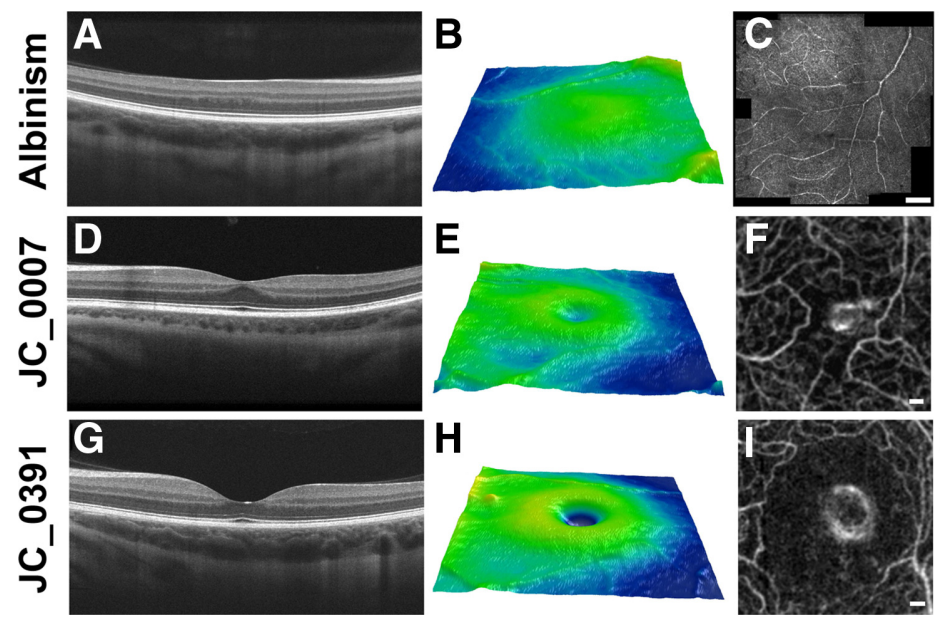

Foveal Pit Depth $0.056 \mathrm{~mm}$ Diameter $1.93 \mathrm{~mm}$ $\begin{array}{rr}\text { Area } & 2.81 \mathrm{~mm}^{2} \\ \text { Volume } & 0.025 \mathrm{~mm}^{3}\end{array}$

No measurable foveal pit or FAZ

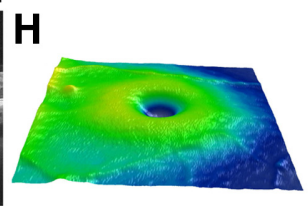

FAZ Diameter $0.40 \mathrm{~mm}$ Area $0.09 \mathrm{~mm}^{2}$

Foveal Pit Depth $0.156 \mathrm{~mm}$ Diameter $2.16 \mathrm{~mm}$ Area $3.66 \mathrm{~mm}^{2}$ Volume $0.126 \mathrm{~mm}^{3}$ FAZ Diameter $1.08 \mathrm{~mm}$ Area $1.05 \mathrm{~mm}^{2}$ 
finding that the normal range of foveal pit morphology overlaps with that seen in albinism (Carroll J, et al. IOVS 2011;52: ARVO E-Abstract 2175) and that, in patients with albinism, pit depth is not a reliable predictor of visual acuity. ${ }^{59}$ This would also suggest that other anatomic features of the visual system underlie visual deficits in albinism, such as reduced outer segment length, reduced cone packing, or disrupted cortical organization. ${ }^{12,59,60}$ Progress on this issue could be made through careful investigation of foveal anatomy (pit morphology, outer segment length, cone density), and corresponding visual acuity measurements could be made using AO. ${ }^{61,62}$

\section{Comparison with Previous Data on the FAZ}

FAZ data presented here are generally consistent with previously published results. In a study using conventional FA, Bresnick et al. ${ }^{13}$ reported a median area of $0.350 \mathrm{~mm}^{2}$ in 20 healthy controls. In a study using a combined SLO and FA approach, Arend et al. ${ }^{63}$ found a mean $( \pm$ SD) area of $0.231 \pm$ $0.060 \mathrm{~mm}^{2}$ in 21 healthy controls. Using high-contrast entoptic viewing of the retinal vasculature to envisage the FAZ in 34 eyes, Bradley et al. ${ }^{38}$ reported a mean area of $0.420 \mathrm{~mm}^{2}$. Using contrast-enhanced FA obtained with an SLO system (Heidelberg Spectralis HRA+OCT; Heidelberg Engineering), John et al. ${ }^{64}$ examined the FAZ in 31 healthy subjects and found a mean $( \pm S D)$ area of $0.275 \pm 0.074 \mathrm{~mm}^{2}$. In a recent study in five subjects using a dual-conjugate $\mathrm{AO}$ fundus camera, a mean $( \pm \mathrm{SD})$ area of $0.302 \pm 0.100 \mathrm{~mm}^{2}$ was reported. ${ }^{44}$ Using an AOSLO device and motion contrast enhancement image processing techniques, Tam et al. ${ }^{43}$ found a mean ( \pm SD) area of $0.323 \pm 0.107 \mathrm{~mm}^{2}$ in 10 persons. The authors of only these most recent studies corrected their FAZ measurements for individual differences in ocular magnification because of variation in axial length. Our mean $( \pm$ SD) area was $0.44 \pm 0.25$ $\mathrm{mm}^{2}$, with a range of 0.05 to $1.05 \mathrm{~mm}^{2}$, which was also corrected for ocular magnification differences. We suspect that the variation in our population is slightly higher than in previous studies given that we targeted subjects known to have foveal pits near the extremes of the normal distribution (we were explicitly interested in the relationship between foveal pit morphology and FAZ size). This fact, combined with differences in age, sex, and race of the populations studied, and the techniques used to measure FAZ make direct comparisons difficult between our study and previous studies. Nevertheless, as with other anatomic specializations of the human foveal region (e.g., cone density ${ }^{65-70}$ and pit morphology ${ }^{28,32-35}$ ), it is clear that there is substantial variation in FAZ size across persons with normal vision. Whether these retinal variations direct the variability seen in primary visual cortex remains unclear, ${ }^{71-74}$ though it seems logical that different distributions of retinal cells could be involved in the normal development of these structures.

\section{Role of the FAZ in Development of the Foveal Pit}

Current models of foveal development suggest that a FAZ is required for complete foveal excavation. ${ }^{17,55,75}$ Supporting this model are data from patients with a history of retinopathy of prematurity, who have shallower foveal pits than normal and absent FAZ. ${ }^{5}$

In support of this view are data from patients with albinism, who also lack FAZ and who have, at best, a subtle foveal depression. Interestingly, other aspects of foveal specialization (such as increased packing of foveal cones, outer segment elongation, and lengthening of Henle's fibers) can reach normal stages in patients with albinism, ${ }^{12,45,59}$ indicating that the presence of a foveal cone pit is not required for complete foveal cone specialization. Nevertheless, our data on 42 subjects provide further support of this view of foveal develop- ment in that we observed a strong correlation between FAZ size and foveal pit morphology; large FAZ was associated with large foveal pits. Such a relationship was also seen in a recent study in 10 persons by Tick et al., though their measurements were not corrected for retinal magnification. ${ }^{28}$

Whether larger FAZ permits enhanced foveal excavation or whether increased foveal excavation modifies FAZ cannot be discriminated from correlative studies such as ours, but given that the FAZ appears before a pit, ${ }^{76}$ it seems more plausible that the size of the FAZ influences the degree of foveal excavation. Of course, a limitation of the present study to address issues concerning the developmental relatedness of the FAZ and the foveal pit is that our data were derived from the adult retina. That said, developmental models do make explicit predictions regarding how these anatomic features should relate in the mature retina; therefore, data such as ours provide useful tests of those predictions. Moreover, we believe that the methodologic approach outlined here could be extended to earlier postnatal ages, when foveal morphology is still changing, especially given the availability of imaging tools with which to assess the neonate retina. ${ }^{77}$

Of further interest is how these aspects of foveal anatomy influence the heterogeneous packing of cone photoreceptors across the macula. The previously mentioned data from patients with albinism would seem to suggest that the increased packing of foveal cones is not entirely dependent on the presence of a defined FAZ or on normal foveal pit. Further support for this is garnered from the discovery of gradients of trophic factors thought to be responsible for initiating and leading the migration of cones and their attached neurons toward the foveal center. ${ }^{78,79}$ A competing model invokes forces in the developing eye, such as retinal stretch and interocular pressure, to facilitate cone packing. ${ }^{17,55}$ Evidence against this model comes from the finding that persons with no foveal pit can have normal cone packing. ${ }^{12,45}$ Given the prominent role of the foveal area in our visual capacity, refining and clarifying current models of foveal development is of great importance. Examining how varying foveal architecture is associated with the well-described variation in foveal cone packing will provide valuable data in this regard. Great strides have been made in the visualization of the cones at the very center of the fovea with AO imaging tools. ${ }^{46,69,80}$ As such, examining the topography of the cone mosaic in persons with disparate foveal pit and FAZ morphology is within our reach.

\section{Acknowledgments}

The authors thank William Fischer, Yusufu Sulai, and Phyllis M. Summerfelt for technical assistance, Austin Roorda and Johnny Tam for helpful discussions and providing the AOSLO FAZ image for JC_0007, and Aniko Szabo for statistical assistance through the Biostatistics Consulting Center at Medical College of Wisconsin.

\section{References}

1. Hendrickson A. Organization of the adult primate fovea. In: Penfold PL, Provis JM, eds. Macular Degeneration. Heidelberg: Springer-Verlag; 2005:1-20.

2. Provis JM, Penfold PL, Cornish EE, Sandercoe TM, Madigan MC Anatomy and development of the macula: specialisation and the volunerability to macular degeneration. Clin Exp Optom. 2005;88: 269-281.

3. Isenberg SJ. Macular development in the premature infant. Am J Ophthalmol. 1986;101:74-80.

4. Mintz-Hittner HA, Knight-Nanan DM, Satriano DR, Kretzer FL. A small foveal avascular zone may be an historic mark of prematurity. Ophthalmology. 1999;106:1409-1413.

5. Hammer DX, Iftimia NV, Ferguson RD, et al. Foveal fine structure in retinopathy of prematurity: an adaptive optics Fourier domain 
optical coherence tomography study. Invest Ophthalmol Vis Sci. 2008;49:2061-2070.

6. Vinekar A, Avadhani K, Sivakumar M, et al. Understanding clinically undetected macular changes in early retinopathy of prematurity on spectral domain optical coherence tomography. Invest Ophthalmol Vis Sci. 2011;52:5183-5188.

7. Gregor Z. The perifoveal vasculature in albinism. Br J Ophthalmol. 1978;62:554-557.

8. Abadi RV, Pascal D. The recognition and management of albinism. Ophthalmic Physiol Opt. 1989;9:3-15.

9. Kinnear PE, Jay B, Witkop CJJ. Albinism. Surv Ophthalmol. 1985; 30:75-101.

10. Oetting WS, Summers CG, King RA. Albinism and the associated ocular defects. Metab Pediatr Syst Ophthalmol. 1994;17:5-9.

11. Seo JH, Yu YS, Kim JH, Choung HK, Heo JW, Kim SJ. Correlation of visual acuity with foveal hypoplasia grading by optical coherence tomography in albinism. Ophthalmology. 2007;114:15471551.

12. McAllister JT, Dubis AM, Tait DM, et al. Arrested development: high-resolution imaging of foveal morphology in albinism. Vision Res. 2010;50:810-817.

13. Bresnick GH, Condit R, Syrjala S, Palta M, Groo A, Korth K. Abnormalities of the foveal avascular zone in diabetic retinopathy. Arch Ophthalmol. 1984;102:1286-1293.

14. Conrath J, Giorgi R, Raccah D, Ridings B. Foveal avascular zone in diabetic retinopathy: quantitative vs qualitative assessment. Eye (Lond). 2005;19:322-326

15. Tam J, Dhamdhere KP, Tiruveedhula P, et al. Disruption of the retinal parafoveal capillary network in type 2 diabetes before the onset of diabetic retinopathy. Invest Ophthalmol Vis Sci. 2011;52: 9257-9266.

16. Elsner AE, Weber A, Cheney MC, VanNasdale DA, Miura M. Imaging polarimetry in patients with neovascular age-related macular degeneration. J Opt Soc Am A. 2007;24:1468-1480.

17. Springer AD. New role for the primate fovea: a retinal excavation determines photoreceptor deployment and shape. Vis Neurosci. 1999;16:629-636.

18. Bone RA, Landrum JT, Fernandez L, Tarsis S. Analysis of the macular pigment by HPLC: retinal distribution and age study. Invest Ophthalmol Vis Sci. 1988;29:843-849.

19. Berendschot TTJM, Willemse-Assink JJM, Bastiaanse M, de Jong PTVM, van Norren D. Macular pigment and melanin in age related maculopathy in a general population. Invest Ophthalmol Vis Sci. 2002; $43: 1928-1932$.

20. Kirby ML, Beatty S, Loane E, et al. A central dip in the macular pigment spatial profile is associated with age and smoking. Invest Ophthalmol Vis Sci. 2010;51:6722-6728.

21. Hammond BR, Caruso-Avery M. Macular pigment optical density in a Southwestern sample. Invest Ophthalmol Vis Sci. 2000;41:14921497.

22. Whitehead AJ, Mares JA, Danis RP. Macular pigment: a review of current knowledge. Arch Ophthalmol. 2006;124:1038-1045.

23. Kimble TDH, Williams RW. Structure of the cone photoreceptor mosaic in the retinal periphery of adult humans: analysis as a function of age, sex, and hemifield. Anat Embryol. 2000;201:305316.

24. Song H, Chui TYP, Zhong Z, Elsner AE, Burns SA. Variation in cone photoreceptor packing density with retinal eccentricity and age. Invest Ophthalmol Vis Sci. 2011;52:7376-7384.

25. Gao H, Hollyfield JG. Aging of the human retina: differential loss of neurons and retinal pigment epithelial cells. Invest Ophthalmol Vis Sci. 1992;33:1-17.

26. Curcio CA, Medeiros NE, Millican CL. Photoreceptor loss in agerelated macular degeneration. Invest Ophthalmol Vis Sci. 1996; 37:1236-1249.

27. Gorrand JM, Delori FC. Reflectance and curvature of the inner limiting membrane at the foveola. J Opt Soc Am A. 1999;16:12291237.

28. Tick S, Rossant F, Ghorbel I, et al. Foveal shape and structure in a normal population. Invest Ophthalmol Vis Sci. 2011;52:51055110.
29. Laatikainen L, Larinkari J. Capillary-free area of the fovea with advancing age. Invest Ophthalmol Vis Sci. 1977;16:1154-1157.

30. Sanders RJ, Brown GC, Rosenstein RB, Magargal L. Foveal avascular zone diameter and sickle cell disease. Arch Ophthalmol. 1991;109: 812-815.

31. Curcio CA, Messinger JD, Sloan KR, Mitra A, McGwin G, Spaide RF Human chorioretinal layer thicknesses measured in macula-wide, high-resolution histologic sections. Invest Ophthalmol Vis Sci. 2011;52:3943-3954.

32. Nolan JM, Stringham JM, Beatty S, Snodderly DM. Spatial profile of macular pigment and its relationship to foveal architecture. Invest Ophthalmol Vis Sci. 2008;49:2134-2142.

33. Dubis AM, McAllister JT, Carroll J. Reconstructing foveal pit morphology from optical coherence tomography imaging. Br J Ophthalmol. 2009;93:1223-1227.

34. Kirby ML, Galea M, Loane E, Stack J, Beatty S, Nolan JM. Foveal anatomic associations with the secondary peak and the slope of the macular pigment spatial profile. Invest Ophthalmol Vis Sci. 2009;50:1383-1391.

35. Wagner-Schuman M, Dubis AM, Nordgren RN, et al. Race- and sex-related differences in retinal thickness and foveal pit morphology. Invest Ophthalmol Vis Sci. 2010;52:625-634.

36. Levi DM, Klein SA, Yap YL. Positional uncertainty in peripheral and amblyopic vision. Vision Res. 1987;27:581-598.

37. Zeffren BS, Applegate RA, Bradley A, van Heuven WAJ. Retinal fixation point location in the foveal avascular zone. Invest $O p h$ thalmol Vis Sci. 1990;31:2099-2105.

38. Bradley A, Applegate RA, Zeffren BS, van Heuven WA. Psychophysical measurement of the size and shape of the human foveal avascular zone. Ophthalmic Physiol Opt. 1992;12:18-23.

39. Zheng Y, Gandhi JS, Stangos AN, Campa C, Broadbent DM, Harding SP. Automated segmentation of foveal avascular zone in fundus fluorescein angiography. Invest Ophthalmol Vis Sci. 2010;51: 3653-3659.

40. Provis JM, Hendrickson AE. The foveal avascular region of developing human retina. Arch Ophthalmol. 2008;126:507-511.

41. Wang Q, Kocaoglu OP, Cense B, et al. Imaging retinal capillaries using ultrahigh-resolution optical coherence tomography and adaptive optics. Invest Ophthalmol Vis Sci. 2011;52:6292-6299.

42. Kim DY, Fingler J, Zawadzki RJ, et al. Noninvasive imaging of the foveal avascular zone with high-speed phase-variance optical coherence tomography. Invest Ophthalmol Vis Sci. 2012;53:85-92.

43. Tam J, Martin JA, Roorda A. Non-invasive visualization and analysis of parafoveal capillaries in humans. Invest Ophthalmol Vis Sci. 2010;51:1691-1698.

44. Popovic Z, Knutsson P, Thaung J, Owner-Peterson M, Sjöstrand J. Noninvasive imaging of human foveal capillary network using dual-conjugate adaptive optics. Invest Ophthalmol Vis Sci. 2011; 52:2649-2655

45. Marmor MF, Choi SS, Zawadzki RJ, Werner JS. Visual insignificance of the foveal pit: reassessment of foveal hypoplasia as fovea plana. Arch Ophthalmol. 2008;126:907-913.

46. Dubra A, Sulai Y, Norris JL, et al. Non-invasive imaging of the human rod photoreceptor mosaic using a confocal adaptive optics scanning ophthalmoscope. Biomed Opt Express. 2011;2:18641876.

47. Merino D, Duncan JL, Tiruveedhula P, Roorda A. Observation of cone and rod photoreceptors in normal subjects and patients using a new generation adaptive optics scanning laser ophthalmoscope. Biomed Opt Express. 2011;2:2189-2201.

48. Izhaky D, Nelson DA, Burgansky-Eliash Z, Grinvald A. Functional imaging using the retinal function imager: direct imaging of blood velocity, achieving fluorescein angiography-like images without any contrast agent, qualitative oximetry, and functional metabolic signals. Jpn J Ophthalmol. 2009;53:345-351.

49. Dubra A, Sulai Y. Reflective afocal broadband adaptive optics scanning ophthalmoscope. Biomed Opt Express. 2011;2:17571768.

50. Dubra A, Harvey Z. Registration of 2D images from fast scanning ophthalmic instruments. Proceedings of the 4th International Conference on Biomedical Image Registration. Heidelberg: Springer-Verlag; 2010:60-71. 
51. Abramoff MD, Magelhaes PJ, Ram SJ. Image processing with ImageJ. Biophotonics Int. 2004;11:36-42.

52. Polyak SL. The Retina. Chicago: The University of Chicago Press; 1941.

53. Yamada E. Some structural features of the fovea centralis in the human retina. Arch Ophthalmol. 1969;82:151-159.

54. Hendrickson AE, Yuodelis C. The morphological development of the human fovea. Ophthalmology. 1984;91:603-612.

55. Springer AD, Hendrickson AE. Development of the primate area of high acuity, 3: temporal relationships between pit formation, retinal elongation and cone packing. Vis Neurosci. 2005;22:171-185.

56. Gupta A, Laxmi G, Nittala MG, Raman R. Structural and functional correlates in color vision deficiency. Eye (Lond). 2011;25:909917.

57. Thomas MG, Kumar A, Mohammad S, et al. Structural grading of foveal hypoplasia using spectral-domain optical coherence tomography a predictor of visual acuity? Ophthalmology. 2011;118: 1653-1660.

58. Walls GL. Significance of the foveal depression. Arch Ophthalmol. 1937;18:912-919.

59. Mohammad S, Gottlob I, Kumar A, et al. The functional significance of foveal abnormalities in albinism measured using spectraldomain optical coherence tomography. Ophthalmology. 2011; 118:1645-1652.

60. von dem Hagen EAH, Houston GC, Hoffman MB, Jeffery G, Morland $\mathrm{AB}$. Retinal abnormalities in human albinism translate into a reduction of grey matter in the occipital cortex. Eur J Neurosci. 2005;22:2475-2480.

61. Rossi EA, Weiser P, Tarrant J, Roorda A. Visual performance in emmetropia and low myopia after correction of high-order aberrations. J Vis. 2007;7:1-14.

62. Rossi EA, Roorda A. The relationship between visual resolution and cone spacing in the human fovea. Nat Neurosci. 2010;13:156157.

63. Arend $\mathrm{O}$, Wolf $\mathrm{S}$, Jung $\mathrm{F}$, et al. Retinal microcirculation in patients with diabetes mellitus: dynamic and morphological analysis of perifoveal capillary network. Br J Ophthalmol. 1991;75:514-518.

64. John D, Kuriakose T, Devasahayam S, Braganza A. Dimensions of the foveal avascular zone using the Heidelberg retinal angiogram-2 in normal eyes. Indian J Ophthalmol. 2011;59:9-11.

65. Curcio CA, Sloan KR, Kalina RE, Hendrickson AE. Human photoreceptor topography. J Comp Neurol. 1990;292:497-523.

66. Duncan JL, Zhang Y, Gandhi J, et al. High-resolution imaging with adaptive optics in patients with inherited retinal degeneration. Invest Ophthalmol Vis Sci. 2007;48:3283-3291.
67. Chui TYP, Song HX, Burns SA. Individual variations in human cone photoreceptor packing density: variations with refractive error. Invest Ophthalmol Vis Sci. 2008;49:4679-4687.

68. Chui TY, Song H, Burns SA. Adaptive-optics imaging of human cone photoreceptor distribution. J Opt Soc Am A. 2008;25:30213029.

69. Li KY, Tiruveedhula P, Roorda A. Intersubject variability of foveal cone photoreceptor density in relation to eye length. Invest $O p h$ thalmol Vis Sci. 2010;51:6858-6867.

70. Duncan JL, Talcott KE, Ratnam K, et al. Cone structure in retinal degeneration associated with mutations in the peripherin/RDS gene. Invest Ophthalmol Vis Sci. 2011;52:1557-1566.

71. Stensaas SS, Eddington DK, Dobelle WH. The topography and variability of the primary visual cortex in man. J Neurosurg. 1974; 40:747-755.

72. Andrews TJ, Halpern SD, Purves D. Correlated size variations in human visual cortex, lateral geniculate nucleus, and optic tract. J Neurosci. 1997;17:2859-2868.

73. Dougherty RF, Koch VM, Brewer AA, Fischer B, Modersitzki J, Wandell BA. Visual field representations and locations of visual areas V1/2/3 in human visual cortex. $J$ Vis. 2003;3:586-598.

74. Wandell BA, Brewer AA, Dougherty RF. Visual field map clusters in human cortex. Philos Trans R Soc Lond B Biol Sci. 2005;360:639707.

75. Provis JM, Diaz CM, Dreher B. Ontogeny of the primate fovea: a central issue in retinal development. Prog Neurobiol. 1998;54: 549-581.

76. Hendrickson A, Provis J. Comparison of development of the primate fovea centralis with peripheral retina. In: Sernagor E, Eglen S, Harris B, Wong R, eds. Retinal Development. Cambridge: Cambridge University Press; 2006.

77. Maldonado RS, O'Connell RV, Sarin N, et al. Dynamics of human foveal development after premature birth. Ophthalmology. 2011; 118:2315-2325.

78. Kozulin P, Natoli R, Bumsted O'Brien KM, Madigan MC, Provis JM. Differential expression of anti-angiogenic factors and guidance genes in the developing macula. Mol Vis. 2009;15:49-59.

79. Kozulin P, Natoli R, Bumsted O'Brien KM, Madigan MC, Provis J. The cellular expression of antiangiogenic factors in fetal primate macula. Invest Ophthalmol Vis Sci. 2010;51:4298- 4306.

80. Putnam N, Hammer D, Zhang Y, Merino D, Roorda A. Modeling the foveal cone mosaic imaged with adaptive optics scanning laser ophthalmoscopy. Opt Express. 2010;18:24902-24916. 